\title{
LUZ INTENSA PULSADA NO TRATAMENTO DE ACNE
}

\section{INTENSE PULSED LIGHT IN ACNE TREATMENT}

\author{
Traudi Klein* \\ Universidade Estadual de Ponta Grossa, Departamento de Ciências Farmacêuticas, Ponta \\ Grossa, Paraná, Brasil. \\ *Autor correspondente: Av. General Carlos Cavalcanti, 4748, Campus Uvaranas - CEP \\ 84030-900, Ponta Grossa PR, Brasil. Fone: (42) 2102 8162, email: tklein@uepg.com.br.
}

\section{RESUMO}

A Luz Intensa Pulsada (LIP) é uma luz policromática de alta intensidade versátil e flexível em suas variáveis e que permite tratar diferentes tipos de lesões cutâneas, realizar epilação e fotorrejuvenescimento. A acne é uma inflamação do folículo pilossebáceo e sua prevalência, complexidade e grau de sofrimento psicossocial do paciente tem levado a disponibilidade de diversos tratamentos tópicos e sistêmicos. O objetivo deste estudo é expor e discutir o tratamento da acne leve a moderada por LIP, buscando comprovações científicas. O estudo teve caráter exploratório, utilizando levantamento bibliográfico em bases de dados e periódicos científicos. Para pacientes que apresentam contraindicações aos tratamentos disponíveis a LIP tem demonstrado efeitos benéficos. Os resultados observados sugerem que a LIP, sozinha ou associada a outros procedimentos, é eficaz no tratamento da acne leve a moderada.

Palavras-chave: Luz intensa pulsada; LIP; Acne; Propionibacterium acnes.

\begin{abstract}
Intense Pulsed Light (IPL) is a high-intensity polychromatic light that is versatile and flexible in its variables and which allows the treatment of different types of skin lesions, epilation and photorejuvenation. Acne is an inflammation of the pilosebaceous follicle and its prevalence, complexity and degree of psychosocial suffering has led to the availability of various topical and systemic treatments. The objective of this study is to present and discuss the treatment of mild to moderate acne by IPL, seeking scientific evidence. The study was exploratory, using bibliographic databases and scientific journals. For patients with contraindications to the treatments available IPL has shown beneficial effects. The results suggest that IPL, alone or associated with other procedures, is effective in treating mild to moderate acne.
\end{abstract}

Keywords: Intense pulsed light; IPL; Acne; Propionibacterium acnes.

\section{Introdução}

A luz intensa pulsada (LIP) surgiu nos anos de 1990. Ela emite luz policromática de alta intensidade, com comprimentos de onda que variam de $400 \mathrm{~nm}$ a $1200 \mathrm{~nm}$, com duração de pulso de dois a 200ms, não coerente e não colimada. O mecanismo de ação é a fototermólise seletiva, ou seja, dano térmico mais ou menos seletivo do alvo ou cromóforo. Pode-se selecionar a faixa de comprimento de onda desejada e a duração de pulso através de filtros, também chamados de cut offs. Somente comprimentos de onda acima do filtro utilizado passam por ele e atingem a superfície cutânea. A possibilidade de variar os comprimentos de onda, as fluências, a duração de pulso e o intervalo entre os mesmos dão versatilidade e flexibilidade à técnica, o que permite que seja usada com vários objetivos, atingindo vários cromóforos. Os três principais cromóforos da pele humana são a hemoglobina, a melanina e a água; cada um desses possui picos específicos de absorção de luz. Assim, a combinação parâmetros possibilita tratar várias lesões 
cutâneas vasculares e melanocíticas, bem como realizar a epilação e o fotorrejuvenescimento (1-3).

É útil quando os pacientes não estão dispostos a assumir os efeitos adversos de outros procedimentos que requerem tempo mais prolongado de recuperação. Assim, a LIP possui excelente relação custo/benefício, atraente tanto para o paciente quanto para o profissional que o executa $(3,4)$.

A acne é uma inflamação do folículo pilossebáceo, caracterizada inicialmente pela presença de um comedão ou "cravo", quando o orifício de saída da unidade pilossebácea fica obstruído com acúmulo de secreções, restos celulares e algumas vezes um ácaro: o Demodex foliculorum. A patogênese é multifatorial e está relacionada aos seguintes fatores: a comedogênese (formação do comedão), a produção de sebo, a colonização bacteriana pelo Propionibacterium acnes (P. acnes) e o processo inflamatório. As glândulas pilossebáceas sofrem uma modificação fundamental para o processo de formação da acne. Há uma hipertrofia de toda a glândula decorrente da ação androgênica sobre sua estrutura, não necessariamente levando à formação de acne, mas criando condições para a formação do comedão. Uma hiperproliferação na porção epidérmica oclui o óstio ductal, impedindo a drenagem do sebo normalmente produzido pela glândula, favorecendo a comedogênese (5-8).

A acne é, provavelmente, a mais frequente doença cutânea, afetando 85 a $100 \%$ da população em qualquer momento da sua vida. A incidência da acne na adolescência varia entre $30-66 \%$, situandose os picos máximos no sexo feminino entre 14-17 anos, e entre 16-19 anos no sexo masculino (9). A grande prevalência, sua complexidade e o grau de sofrimento psicossocial do paciente, principalmente na adolescência, trazem a necessidade de outros especialistas, além do dermatologista, conhecerem a físiopatologia e as opções atuais de tratamento. Diversos tratamentos tópicos e sistêmicos estão disponíveis e cada paciente se adapta a um tipo de tratamento. É preciso avaliar o custo e o benefício das drogas e procedimentos disponíveis, e as melhores indicações conforme o aspecto clínico das lesões. Uma combinação de terapias consegue um melhor cumprimento da terapia e eficácia duradoura $(1,5,8,9)$.

Embora não seja "primeira linha" no tratamento de acne inflamatória leve a moderada, a LIP é opção naqueles pacientes que apresentam contraindicações aos tratamentos disponíveis e pode ser associada aos tratamentos tópicos. A técnica tem sido citada como opção no tratamento das cicatrizes de acne, principalmente quando eritematosas e hipertróficas, com a vantagem da ausência de púrpura e da maior superfície tratada, porém, considerada mais dolorosa $(3,6)$.

Assim, devido a versatilidade da técnica de LIP e a necessidade de maior número de tratamentos para acne disponíveis para pacientes acometidos, o objetivo do estudo foi fazer um levantamento bibliográfico sobre o assunto, expor e discutir o tratamento da acne leve a moderada por LIP, buscando comprovações científicas em periódicos e bases de dados.

\section{Metodologia}

O estudo teve caráter exploratório, utilizando levantamento bibliográfico em bases de dados e periódicos científicos.

Delimitou-se a pesquisa incluindo (a) estudos publicados posteriormente a 2006; (b) que estavam disponíveis para consulta online; (c) com acesso ao conteúdo completo; (d) com os indexadores "Acne", "Luz Intensa Pulsada" e ambos. Foram selecionados alguns estudos que se relacionavam entre si a respeito dos indexadores utilizados.

\section{Resultados}

A LIP é uma alternativa aos lasers para o tratamento de diversos tipos de lesões vasculares, rosácea, telangiectasias, poiquilodermia de civatte, estrias, cicatriz hipertrófica e queloide, angioqueratomas, hemangioma, mancha vinho do porto, dermatite ocre, lesões melanocíticas, melanoses solares, efélides, nevo de ota, hiperpigmentação infraorbitária (olheiras), hiperpigmentação pósinflamatória, melasma, nevo de Becker; bem como para epilação e fotorrejuvenescimento não ablativo. Além disso, é útil como mais uma opção para acne, terapia fotodinâmica, aumento da absorção/permeação de ativos, sarcoidose, onicomicose, cisto pilonidal, hidradenite supurativa. A associação de tecnologias, com o uso LIP, lasers e peelings químicos é possível e interessante, de acordo com o objetivo terapêutico. A combinação de técnicas resulta em maior praticidade, com menor número de sessões necessárias. A técnica tem sido bastante utilizada como auxiliar ao tratamento tópico e sistêmico da acne. O número de sessões e 
o tempo de tratamento vão variar de acordo com as características da acne, sua localização, o grau de manifestação clínica, além da presença ou não de cicatrizes (2-4,8). Li e Chen, 2008 (10) retrataram diversos estudos onde concluíram que a técnica tem sido amplamente utilizada no tratamento de uma variedade de doenças da pele na população chinesa, com excelentes melhorias e efeitos colaterais limitados. Outros autores demonstraram a eficácia do tratamento em indianos, com pouco risco de efeitos colaterais (11).

Os efeitos secundários da LIP são hiper e hipopigmentação, atrofia, bolhas, cicatrizes hipertróficas e quelóides. Em comprimentos de onda de elevada energia na área do infravermelho, principalmente acima de $950 \mathrm{~nm}$, há mais afinidade com a água e consequentemente contribui para o aquecimento epidérmico e dérmico que se estende a uma profundidade de 1,5 a $3 \mathrm{~mm}$, que não é desejado e pode levar aos efeitos indesejados (2-4).

Os sistemas de LIP que emitem luz em duas bandas de comprimento de onda 400-700 nm e 870$1200 \mathrm{~nm}$ são usados na terapêutica da acne, pois atuam simultaneamente nas glândulas sebáceas e nas bactérias. Dois mecanismos de ação da LIP promovem melhora da acne: o primeiro é o efeito fotodinâmico pela luz visível e pelo espectro ultravioleta (UV) que são absorvidos pelas porfirinas produzidas pelo $P$. acnes, que culminam com a formação de radicais livres de oxigênio (ROS, reactive oxygen species) responsáveis pelo efeito bactericida; o segundo mecanismo baseia-se na fototermólise seletiva dos vasos sanguíneos que nutrem a glândula sebácea: ao reduzir o fluxo sanguíneo, a taxa de secreção da glândula sebácea decresce. Um terceiro mecanismo de ação requer um fotossensibilizador exógeno que é aplicado na superfície da pele. O fotosensibilizador acumula-se nas glândulas sebáceas e leva à destruição das glândulas após a ativação da luz $(2,3,6,8)$.

Um estudo comparando tratamento com peróxido de benzoíla (PB) e LIP resultou em melhoria considerável da acne após cinco semanas de tratamento em ambas as terapias. O PB produziu melhores resultados do que LIP, no entanto, essa diferença foi insignificante no final do estudo. Os resultados contribuem com a evidência de LIP como uma opção terapêutica útil para o tratamento de acne leve a moderada e valida estudos adicionais para avaliar o tratamento em um maior número de pacientes e por longos períodos. É uma ferramenta eficaz e bem tolerada, porém seu alto custo limita o uso (8).

Para estudar a eficácia da LIP no tratamento da acne vulgar, vinte e cinco pacientes foram submetidos a LIP. A técnica foi aplicada a cada 2 semanas por 4 sessões. Todos os pacientes apresentaram redução no número de lesões de acne após as 4 sessões. Não foram observados efeitos colaterais significativos. Os pacientes também observaram uma melhora na textura da pele (12).

Com o objetivo de determinar a eficácia e segurança da LIP no tratamento de acne vulgar moderada, setenta e cinco pacientes foram submetidos a terapia uma vez por semana durante quatro semanas. Nenhum dos pacientes apresentou efeitos colaterais graves na visita de acompanhamento final. Os autores sugerem que a LIP é segura e eficaz em mais de metade dos pacientes no tratamento de acne vulgar leve e moderada. Propõem um estudo em longo prazo para determinar a segurança após esses procedimentos (13). Quarenta e cinco pacientes na faixa etária de 16 a 28 anos com acne vulgar inflamatória facial foram incluídos em outro estudo. O trabalho comparou duas fluências - uma normal e outra subnormal no lado direito e esquerdo da face, respectivamente. Todos os pacientes receberam 4 sessões em intervalos de 2 semanas e foram seguidos por 2 meses a cada 2 semanas. Não houve diferença estatisticamente significativa na eficácia de duas fluências. A fluência subnormal é tão eficaz quanto a fluência normal na pele indiana. A técnica é uma opção segura e eficaz para acne vulgar inflamatória com efeitos colaterais reversíveis mínimos (14).

Avaliando a LIP como ativador de fotossensibilizador exógeno no tratamento da acne, pesquisadores avaliaram vinte e dois pacientes com acne moderada a grave. Os pacientes foram distribuídos aleatoriamente para receber terapia fotodinâmica com ácido 5-aminolevulínico (ALA-PDT) com fotoativação por LIP (600-850 nm), uma combinação de energias LIP (580-980 nm) e de radiofrequência bipolar (RF), ou luz azul $(417 \mathrm{~nm})$. Cada paciente recebeu 3 sessões ALA-PDT em intervalos de 2 semanas. ALA-PDT com ativação por LIP parece proporcionar uma melhoria maior, mais duradoura e mais consistente do que RFLIP ou ativação de luz azul no tratamento de acne vulgar moderada a grave (15). 
Estudo comparou a eficácia do modo pulso múltiplo com modo de pulso único no tratamento da acne e avaliou a eficácia da LIP no tratamento da acne facial. Dez pacientes com acne facial foram submetidos a monoterapia com LIP e esta, como monoterapia, mostrou efeito benéfico no tratamento. O modo pulso múltiplo foi melhor do que o modo de pulso único na melhora da acne (16).

Pesquisadores avaliaram os efeitos clínicos e histológicos do tratamento com LIP em $420 \mathrm{~nm}$ em acne em modelo animal. Os níveis de fator de necrose tumoral alfa (TNF- $\alpha$ ) e de metaloproteinase de matriz 2 (MMP-2), marcadores de inflamação implicados na acne, foram avaliados em animais tratados e não tratados por imunohistoquímica e reação em cadeia da polimerase (PCR). O tratamento com luz intensa pulsada de $420 \mathrm{~nm}$ levou a uma melhoria acentuada após seis tratamentos quinzenais. A técnica em 420 $\mathrm{nm}$ pode exercer seus efeitos benéficos sobre a acne inflamatória, reduzindo os níveis de $P$. acnes e secundariamente reduzindo a inflamação induzida pela bactéria (17).

Vinte pacientes com acne facial foram tratados usando LIP em um lado da face e laser no outro para comparar a eficácia e segurança. $\mathrm{O}$ tratamento foi realizado 4 vezes em intervalos de 2 semanas. A eficácia do tratamento foi determinada utilizando contagens de lesões, gravidade da acne, autoavaliações subjetivas de melhora do paciente e exames histopatológicos, que incluíram coloração imuno-histoquímica para fator de crescimento transformador-b (TGF-b). Para lesões inflamatórias tais como pápulas, pústulas e nódulos, os lados tratados com LIP mostraram uma melhoria mais cedo e mais profunda do que os lados tratados com laser. As duas técnicas foram consideradas eficazes no tratamento da acne (18).

Um estudo descritivo para avaliar o efeito do LIP na acne vulgar em pacientes indianos, onde 10 pacientes receberam no máximo cinco sessões de tratamento, relatou os seguintes resultados: dois pacientes desistiram, sete pacientes tiveram uma boa resposta após uma média de 3 a 4 sessões; $87,5 \%$ dos pacientes expressaram satisfação com o procedimento. Nenhum efeito adverso foi notado. Autores sugerem que a LIP tem um papel útil no tratamento da acne vulgar e pode reduzir os custos do tratamento e a farmacoterapia. Não há aumento do risco de efeitos colaterais com LIP na pele indiana com o tratamento (11).

\section{Conclusão}

A LIP vem sendo utilizada nas mais variadas áreas da medicina estética e tem demonstrado um papel importante no tratamento da acne. Nesta, age na lesão destruindo as bactérias causadoras da inflamação, acelerando o processo de cicatrização. Os estudos científicos sugerem que a LIP é eficaz no tratamento da acne e que quando associada a outras técnicas e tratamentos pode proporcionar uma melhora ainda maior e mais significativa na patologia e em suas cicatrizes.

\section{Referências}

1 Babilas P, Schreml S, Szeimies RM, Landthaler M. Intense Pulsed Light (IPL): A Review. Lasers in Surgery and Medicine 2010;42:93-104.

2 Catorze MG. Laser: fundamentos e indicações em dermatologia. Med Cutan Iber Lat Am 2009; 37(1):5-27.

3 Kalil CLPV, Reinehr CPH, Milman LM. Luz intensa pulsada: revisão das indicações clínicas. Surg Cosmet Dermatol 2017; 9(1):9-17.

4 Wat H, Wu DC, Rao J, Goldman MP. Application of Intense Pulsed Light in the Treatment of Dermatologic Disease: A Systematic Review. Dermatol Surg 2014;40:359-377.

5 Brenner FM, Rosas FMB, Gadens GA, Sulzbach ML, Carvalho VG, Tamashiro V. Acne: um tratamento para cada paciente. Rev. Ciênc. Méd 2006; 15(3):257-266.

6 Cohen BE, Brauer JA, Geronemus RG. Acne scarring: A review of available therapeutic lasers. Lasers Surg Med 2016;48(2):95-115.

7 Costa A, Moisés TA. Acne e dieta: verdade ou mito? An Bras Dermatol 2010;85(3):346-53.

8 El-Latif AA, Hassan FA, Elshahed AR, Mohamed AG, Elsaie ML. Intense pulsed light versus benzoyl peroxide $5 \%$ gel in treatment of acne vulgaris. Lasers Med Sci 2014;29(3):1009-15.

9 Figueiredo A, Massa A, Picoto A, Soares AP, Basto AS, Lopes C, Resende C, Rebelo C, Brandão FM, Pinto GM, de Oliveira HS, Selores M, Gonçalo M, Bello RT. Avaliação e tratamento do doente com acne - Parte I: Epidemiologia, etiopatogenia, clínica, classificação, impacto psicossocial, mitos e realidades, diagnóstico diferencial e estudos complementares. Rev Port Clin Geral 2011;27:59-65.

$10 \mathrm{Li} \mathrm{YH}$, Chen HD. Clinical application of intense pulsed light in Asian patients. J Appl Cosmetol 2008;26:105-111. 
11 Mohanan S, Parveen B, Malathy PA, Gomathi N. Use of intense pulse light for acne vulgaris in Indian skin - a case series. Inter J Dermatol 2012;51:473-476.

12 Puttaiah M, Jartarkar SR. Intense pulsed light: A promising therapy in treatment of acne vulgaris. Our Dermatol Online 2017;8(1):6-9.

13 Khan WZ, Butt G, Altaf F. Efficacy and safety of intense pulsed light in the treatment of mild-to-moderate acne vulgaris. J Surg Dermatol 2017; 2(T1):152-157

14 Patidar MV, Deshmukh AR, Khedkar MY. Efficacy of Intense Pulsed Light Therapy in the Treatment of Facial Acne Vulgaris: Comparison of Two Different Fluences. Indian J Dermatol 2016; 61(5): 545-549.

15 Taub AF. A comparison of intense pulsed light, combination radiofrequency and intense pulsed light, and blue light in photodynamic therapy for acne vulgaris. J Drugs Dermatol 2007;6:1010-6.

16 Kumaresan M, Srinivas CR. Efficacy of IPL in treatment of acne vulgaris: comparison of single- and burst-pulse mode in IPL. Indian J Dermatol 2010;55(4):370-372.

17 Fan X, Xing YZ, Liu LH, Liu C, Wang DD, Yang RY, Lapidoth M. Effects of 420-nm intense pulsed light in an acne animal model. Eur Ac Dermatol Vener 2012;1-4.

18 Choi YS, Suh HS, Yoon MY, Min SU, Lee DH, Suh DH. Intense pulsed light vs. pulsed-dye laser in the treatment of facial acne: a randomized split-face trial. J Eur Ac Dermatol Vener 2010;24:773-780. 